\title{
COMPARING HEDGES USED BY ENGLISH AND INDONESIAN SCHOLARS IN PUBLISHED RESEARCH ARTICLES: A CORPUS-BASED STUDY
}

\author{
I Nyoman Suka Sanjaya \\ (suka.sanjaya@gmail.com) \\ Anak Agung Raka Sitawati \\ (apute@yahoo.com) \\ Ni Ketut Suciani \\ (inss159@outlook.com) \\ Politeknik Negeri Bali \\ Jl. Raya Kampus Bukit Jimbaran, Kuta Selatan, Badung, Indonesia
}

\begin{abstract}
The study examines whether English and Indonesian research articles written by their respective native speaker scholars are significantly different from each other in terms of the number of hedges used. Hedges are rhetorical features (e.g. may, perhaps, suggest) used to withhold complete commitment to the truth-value of propositions. The ultimate goal of the study is to examine whether Indonesian scholars need special instruction in hedging propositions. The assumption underlying the present study is that when they write in English, Indonesian scholars will deploy rhetorical features inherent in the Indonesian academic writing. Statistical analysis on 52 Applied Linguistics research articles (26 from each language) reveals that English research articles contain significantly more hedges than their Indonesian counterparts (Mann-Whitney $U=68.00, \mathrm{n} 1=\mathrm{n} 2=26, p<0.05, r=-0.69$ ), suggesting that Indonesian scholars are indeed in need of instruction that specifically focuses on hedging propositions in English.
\end{abstract}

Keywords: hedges, Indonesian research articles, English research articles, rhetorical need analysis

DOI: http://dx.doi.org/10.15639/teflinjournal.v26i2/209-227 
Needs analysis, an indispensable component of any English for Academic Purposes (EAP) course, can sufficiently be defined as the process of identifying what language and skills a group of learners need to learn and how they will learn them (Basturkmen, 2010; Flowerdew, 2013). Over the last decade, a myriad of studies were specifically designed to examine the English language needs of non-native speakers. Some of these studies collected the data by means of a single research method, such as semi-structured interviews (İnceçay \& İnceçay, 2010; Jackson, 2005; Kaewpet, 2009; Lehtonen \& Karjalainen, 2008), diagnostic test (Read, 2008), questionnaires (Bacha \& Bahous, 2008; Bosuwon \& Woodrow, 2009; Kassim \& Ali, 2010; H. H. Kim, 2013; S. Kim, 2006; Rostami \& Zafarghandi, 2014; Taillefer, 2007), and analysis of course syllabi (Cooper \& Bikowski, 2007). Other studies, following the suggestion given by Long (2005a), have employed more than one method, that is adopting methodological triangulation (Atai \& Nazari, 2011; Atai \& Shoja, 2011; Chostelidou, 2010; Cowling, 2007; Gözüyeşil, 2014; Klimova, 2014; Lambert, 2010; Long, 2005b; Mazdayasna \& Tahririan, 2008; Moslemi, Moinzadeh, \& Dabaghi, 2011; Paci, 2013; Spence \& Liu, 2013; Stocker \& Reddad, 2013).

With the exception of the study carried out by Miller (2011) that identifies the reading skills needed by second language (L2) students, virtually no study carried out over the last decade made any attempt to analyze authentic texts (either spoken or written, or both) with which the target students would have to deal. Surprisingly, even studies carried out to analyze the English language skills of faculty members in their research work, for example when publishing research articles (e.g. Klimova, 2014), did not include analysis of authentic texts. Particularly, no study focuses its analysis on the academic English language needs of Indonesian students. This strongly suggests that EAP programs in Indonesia have thus far been conducted based on the presently unjustified teachers' intuition (i.e. what works in other contexts also works in Indonesia), rather than on research findings (see Long, 2005a).

The present study attempted to fill this lacuna by examining the English academic writing skills that Indonesian academics need when publishing their research in international journals. In particular, the study was geared towards investigating to what extent English and Indonesian scholars differ significantly from each other in terms of their frequency of hedges when writing research articles in their respective L1s. The pedagogical significance of the study concerns the desirability of providing Indonesian academics with pedagogical intervention specifically focusing on how to hedge (i.e. mitigate) their proposi- 
tions when writing research articles for international publication. In order to do so, a corpus of research articles written in English was rigorously compared to a corpus of research articles written in Indonesian with regards to the frequency of hedges used. The underlying assumption of the present study is that when writers write in their L2, they will use rhetorical structures associated with their native language (cf. Alonso, Alonso, \& Mariñas, 2012). Thus, the analysis of the Indonesian research articles could be argued to represent present situation analysis, while the analysis of the English research articles could be seen as target situation analysis, the two types of analyses conducted in any needs analysis study (Hyland, 2006).

The constant pressure to publish in prestigious international scholarly journals (i.e. journals that are indexed in citation indexes published by Thomson Reuters) "has grown tremendously worldwide over the past thirty years or so" (Salager-Meyer, 2014, p. 79). Although not yet determined as a major criterion for promotion, international publications are accorded higher status in the Indonesian academic rewards system. In fact, to be considered as a Professor (i.e. the highest academic rank in the Indonesian academic ranking system) a lecturer needs to publish certain number of articles in international journals with sufficiently high impact factors. Not only that, Indonesian academic reward system has also recently determined that in order to climb to a certain academic rank a lecturer holding a master's degree needs to have at least one research article published in an international journal. This situation certainly requires Indonesian to have rhetorical skills necessary for international publications. One such rhetorical skill is knowledge of hedges, as explained below.

Hedges, broadly defined as linguistic devices used to downgrade the force of a proposition (e.g. perhaps, seem, likely), constitute important rhetorical features in English written academic discourse (Hyland, 2009). Research shows that an argument presented in a way that is open to debate and discussion (through various hedging devices) is thought of being more convincing and credible than a categorical one (Abbuhl, 2006; Dafouz-Milne, 2008).

The present study draws on the sociocultural model of literacy that posits that "literacy is a social practice ... always embedded in socially constructed epistemological principles" (Street, 2003, p. 77). As such, literacy is not a mental phenomenon, as advocated by adherents of traditional cognitive psychology, but rather a sociocultural one (Gee, 2012). It implies that in producing an academic written text writers are engaged in social and cultural practices. Of particular relevance to the present study is the argument that written texts and so- 
ciocultural contexts are inextricably linked. This leads us to characterize academic literacy not as a single monolithic entity, but rather as many things in different contexts and cultures.

The objectives of the present study are two-fold: first, to examine whether English and Indonesian scholars hedge their propositions to the same extent when they report their research in scholarly journals; second, to introduce the use of corpus method in needs analysis research, a method which has not yet attracted the attention of needs analysts. The practical (i.e. pedagogical) significance of the present study is to inform EAP practitioners in Indonesia about whether or not training to hedge proposition is to be included into their programs, especially those designed to meet English rhetorical skills needed by Indonesian scholars.

The article is structured as follows: the description of method used in the study is discussed in the following section, and subsequently, the study's findings are presented and interpreted. Finally, in the concluding section, limitations of the study are briefly described and suggestions for future research are delivered.

\section{METHOD}

The present study was part of a larger contrastive rhetoric study aimed at examining the effects of sociocultural contexts and disciplinary fields on the use of hedges and boosters in research articles. The corpus for the present study was generated from 52 research articles taken from the discipline of Applied Linguistics written in English ( $\mathrm{n}=26 ; 177,322$ words long) and Indonesian ( $\mathrm{n}$ $=26 ; 105,246$ words long) by the native speakers of the respective languages. The native speakership of the authors was determined on the basis of their name, or the name of the first author in the case of multi-authored research articles. The corpus size was determined on the basis of an a priori power analysis conducted (see Larson-Hall, 2010). The means (M) and standard deviations (SD) of the lengths of the articles included in the two corpora were as follows: English $(\mathrm{M}=6,820.08$ words; $\mathrm{SD}=1,050.73$ words $)$ and Indonesian $(\mathrm{M}=$ $4,047.92$ words; $\mathrm{SD}=1,105.29$ words).

The target population of the study was, therefore, all research articles from the discipline written by native speakers of the two languages. Nevertheless, for purely logistical reasons, the target population was operationally defined in the present study as all research articles from Applied Linguistics written by 
the native speakers of the two languages published in two online journals between 2007 and 2010. The collection of all research articles making up the target population constituted the sampling frame for the study, accordingly. The English articles were drawn from Applied Linguistics (published by Oxford University Press) and International Journal of Applied Linguistics (WileyBlackwell), whereas the Indonesian articles were taken from Linguistika (Udayana University Press) and Logat (North Sumatera University Press). It is to be noted that the issues addressed in the articles written in the two languages were relatively comparable, so any rhetorical difference found was not a function of thematic difference.

The term 'research article' in the present study refers to scholarly article reporting on empirical research published in a journal. Thus, other types of articles typically found in a journal (e.g. literature reviews, opinion articles, book reviews) were not included in the corpus.

To ensure the representativeness of the two specialized corpora used for the present study (Indonesian and English), a simple random sampling technique (Schreiber \& Asner-Self, 2011) was deployed to derive the sample from the target population. A complete master list of the full set of research articles written by applied linguists published over the four-year period was created (N $=90$ ). Subsequently, with the help of True Random Number Generator program (http://www.random.org), a probabilistic sample of texts was generated.

The entire corpus was generated from the following research articles sections: Introduction, Theoretical Framework (Literature Review), Results, Discussion, and Conclusion. The majority of the articles published in the English and Indonesian journals included in the corpus had all these sections. Introduction is the area where the author has to emphasize that the research being reported on is indeed significant (Swales, 1990), and hence serves an ideal place to use hedges. In the theoretical Framework/ Literature Review, the author typically delivers an argument on the fact that previous research cannot solve the problem being discussed in the article, a rhetorical move that undoubtedly triggers the use of hedges. In the Discussion and Conclusion sections, the author, respectively, interpret and propose the implications (theoretical or practical, or both) of the findings presented in the Results section, a rhetorical activity that involves speculation, and hence modalization of propositions is almost inevitable. The inclusion of Results section into the corpus was largely triggered by the fact that the Results and Discussion sections are sometimes merged into 
one section in the Indonesian articles, rather than two as in the case in the English articles.

A combination of manual and computer-based searches was employed to identify hedges in the corpus. First, over 25 percent of the articles from each of the two languages (i.e. seven articles from English articles and seven from Indonesian) were thoroughly read to identify the hedges used. Then, two independent lists of lexical hedges were generated from this manual reading: Indonesian list and English list. These two lists of lexical hedges were subsequently used as the basis for the computer-based search in the rest of the respective corpora (English corpus and Indonesian corpus). The search was done with the help of the Advanced Search function in the Adobe Acrobat Professional X program.

The approach adopted in the process of identifying hedges was a semantic-pragmatic one. That is, the determination of a linguistic device as a potential hedging device was entirely based on the semantic and pragmatic content of the proposition containing it. Consequently, attention was not specifically paid to those linguistic items that had been recognized as hedges in previous studies, but rather all lexical items contained in a proposition were inspected carefully to determine whether they semantically and pragmatically serve as hedges.

In the identification of hedges, the definition of a hedging device proposed by Hyland (1996) was strictly adhered to: "A hedge is ... any linguistic means used to indicate either (a) a lack of complete commitment to the truth of a proposition, or (b) a desire not to express that commitment categorically" ( $p$. 251). Any hedge found in a sentence used by the author(s) to cite other authors' viewpoint was excluded from the analysis, since the author(s) merely reported the tentative statement of the cited author, rather than stating their own viewpoint. In other words, the hedge did not represent the author's own voice. Finally, when two or more hedges were used in the same proposition, all were included in the count.

As could easily be expected, the lengths of the research articles (measured in words) within and across languages were not the same. Biber (2009, p. 1299 ) is right when he mentions that when examining the counts of features across texts "it is important to make sure that the scores are comparable." For this reason alone, the analysis was conducted on the normalized, rather than the absolute or raw, occurrences of hedges. The counts of hedges in the present study were normed to a basis per 1,000 words of text, and the following normalization formula was used: 
Sanjaya, Sitawati, \& Suciani, Comparing Hedges in Published Research Articles 215

$$
\frac{N \text { of occurrences of hedges in a text }}{N \text { of words of the text }} \times 1,000
$$

For example, if 89 hedges were found in a text of 7,503 words the normalized frequency of the hedges in the text in question is 11.86 (rounded up to two decimals).

To reiterate, the research question of the present study is the following: "Do English Applied Linguistics research articles contain significantly more hedges than Indonesian Applied Linguistics research articles?"

This research question is concerned with comparison between two scores, namely the score on average frequency of hedges in English research articles and that of average frequency of hedges in Indonesian research articles. The statistical tool employed to answer this research question was Mann-Whitney $\mathrm{U}$ test, that is the non-parametric test used to determine whether two groups of scores are significantly different from each other (Corder \& Foreman, 2014). This statistical test was used since the data were not normally distributed, as indicated by the results of normality test using Kolmogorov-Smirnov test: English $(\mathrm{D}=0.22, \mathrm{n}=26, p<0.05)$ and Indonesian $(\mathrm{D}=0.26, \mathrm{n}=26, p<0.05)$. All the statistical analyses were carried out with the help of SPSS (Statistical Package for Social Sciences) version 20. To determine the magnitude of difference (if there was any significant difference) between the two groups of research articles, effect size was also calculated. Following Field (2013), the following equation was used to manually compute the effect size estimate for Mann-Whitney U test:

$$
r=\frac{Z}{\sqrt{N}}
$$

where:

$r=$ effect size estimate

$\mathrm{Z}=\mathrm{z}$-score obtained from the SPSS output, and

$\mathrm{N}=$ the sample size involved

\section{FINDINGS AND DISCUSSION}

This section presents the quantitative results of the present study and their interpretation. After the presentation of descriptive and inferential statistics of 
the data, this section proceeds to discuss those results in the light of the theoretical framework adopted in the study and the results of previous studies. Finally, the pedagogical implication is offered.

A total of 1,808 hedges could be identified in the English corpus. As such, since the corpus contained 26 research articles, on average a single English article contained 69.54 hedges. A different picture emerged in the Indonesian corpus. Compared to the English corpus, the Indonesian corpus contained lower number of hedges. The total of 429 hedges found in the Indonesian corpus indicated that on average in a single Indonesian article 16.5 hedges were used. The difference in the total hedging devices found in the two corpora under study can be explained in terms of the differing lengths of research articles included in the two corpora. Although not always necessarily the case, it is reasonable to argue that the longer the text the greater the chances that it contains such devices at a greater frequency rate. The followings are sample sentences from each of the two corpora containing hedges (hedging devices underlined):

(1) ... it may indicate the vocabulary size necessary to understand a text as well as to incidentally learn words in the text.

(2) Bahasa yang digunakan dalam komunikasi pada umumnya tidak bersifat monolitis.

As illustrated by the examples above, the English corpus contained more sentences using more than one hedge, suggesting that compared to their Indonesian colleagues the English applied linguists were much more cautious in presenting their claims.

Per 1,000 words, the minimum number of hedges used in the English corpus was 4.22 , which was higher than the minimum number of hedges found in the Indonesian corpus, 1.03. Therefore, it is clear that all articles in the two corpora contained hedges. A similar picture also emerged with regard to the maximum number of hedges used. The maximum number of hedges found in the English corpus was 27.76, more than nine devices higher than the maximum number of hedges observed in the Indonesian corpus (18.50). The maximum number found in the English corpus turned out to be an extreme value or outlier. It was also true of the maximum number of hedges identified in the Indonesian corpus.

The mean number of hedges used in a 1,000-word text in the English corpus was 10.20 and the standard deviation was 4.69 , whereas in the correspond- 
ing Indonesian corpus the mean number was 4.43 and the standard deviation was 3.69. On the face of it, it seemed that the English applied linguists used more hedges in their research articles. As indicated by the standard deviations, the two data sets were not equal in their dispersion. The slightly smaller magnitude of standard deviation of the Indonesian data set showed that its data values were slightly more concentrated around the mean compared to the data values for the English data set. This in turn indicated that the Indonesian applied linguists were slightly more homogeneous in terms of frequency of usage of hedges in their research articles. The descriptive statistics of the usage of hedges in the English and Indonesian are summarized in the following table.

Table 1. Descriptive Statistics (per 1,000 words)

\begin{tabular}{llllll}
\hline Language & $\mathbf{N}$ & Minimum & Maximum & Mean & Std. Deviation \\
\hline English & 26 & 4.22 & 27.26 & 10.20 & 4.69 \\
Indonesian & 26 & 1.03 & 18.50 & 4.43 & 3.69 \\
\hline
\end{tabular}

As mentioned above, since the data sets summarized in Table 1 did not satisfy the parametric assumption of normal distribution, they were analyzed using the non-parametric version of the test used to compare two sets of data, namely the Mann-Whitney U test. The result of the statistical test revealed that the mean of the English data set was significantly different from the mean of the Indonesian data set (Mann-Whitney $U=68.00, \mathrm{n} 1=\mathrm{n} 2=26, p<0.05, r=$ $0.69)$. This result strongly indicated that the English applied linguists publishing in international journals used hedges significantly more frequently in their research articles than their Indonesian counterparts (English mean rank = 36.88; Indonesian mean rank $=16.21$; see also Table 1 above). The magnitude of the effect size showed that the difference between the two means were large, which could be translated as the large difference between the two groups of applied linguists in terms of their rhetorical behavior when they wrote scholarly articles in their respective native languages. That is, English applied linguists were much more tentative in their propositions than the Indonesian applied linguists. In other words, the statements made by the Indonesian scholars were much more categorical compared to the statements made by their English counterparts.

The paucity of hedging devices in the Indonesian research articles strongly suggests that, unlike their English counterparts, the Indonesian applied linguists 
may perceive things in the world as either black or white. This may be triggered by their negative perception towards uncertainty. It is to be noted that hedging devices are in fact uncertainty markers. The widespread belief circulating among the Indonesian scholars might be that hedging usage is a sign of one's lack of knowledge. The rhetorical patterning of research article's Introduction section written in Indonesian provides evidence that the expertise of a researcher (and the absolute authority which comes with it) is not supposed to be questioned. Adnan (2008) showed that none of the 63 article introductions he analyzed contained critical evaluation of the previous studies. Adnan argued that such absence of critical comments on previous studies is the upshot of the Indonesian cultural values which consider criticism as unethical. Although this explanation is undoubtedly legitimate, it could also be argued that it is by virtue of the unstated beliefs (i.e. cultural models) which regard researchers (in this case, university teachers) as experts who are not supposed to be challenged, or even criticized. English scholars in the present study, by contrast, did not seem to see themselves as being endowed with absolute authority, and hence they did not operate within the same cultural model as the Indonesian scholars. Granted, English scholars are also perceived as experts in their field, but such status is quite different from the status as experts ascribed to their Indonesian fellows; the difference lies in its vulnerability to criticisms. Analysis of any English research article's Introduction will provide solid evidence which suggests that the expertise of English scholars is susceptible to criticism. When a writer attempts to fill a knowledge gap, he or she typically argues that what has been done by previous researchers is limited, which is clearly a negative evaluation geared towards those previous researchers (Swales, 1990). This might trigger the more frequent use of hedges in the English research articles.

It should be borne in mind that Indonesian scholars are not the only group of scholars who holds such a belief. Alonso et al. (2012) also found that native speakers of Spanish negatively perceive hedging as a sign of lack of commitment to the truth-value of the propositions presented. Therefore, it would not be unreasonable to argue that the rhetorical behavior displayed by a writer and the worldviews he or she adopts are intertwined. As in the words of Gee (2012, p. 77), "what is at issue in the use of language is different ways of knowing and different ways of making sense of the world of human experience." The English and Indonesian researchers in the present study seemed to adapt to different ways of understanding, interpreting and organizing knowledge. What it all boils down to is the claim advanced in the sociocultural 
approach to literacy that literacy, or for that matter academic literacy, is not to be considered a singular thing but as a plural set of social practices.

Gee (2015, p. 40) convincingly argued that: "Any technology, including writing, is a cultural form. It is a social product whose shape and influence depend upon prior political and ideological factors." The differential rhetorical characteristics inherent in the two groups of research articles are the byproduct of the similar differential prevailing ideologies (i.e. beliefs and value systems) valorized by the two sociocultural contexts within which the two groups of researchers operate. Within the Indonesian sociocultural context, the prevailing ideology might be that ideas should be stated with conviction, whereas within the English sociocultural context the dominant ideology might be that ideas should be embraced with sufficient caution. It is to be noted that not all Indonesian and English researchers adopt the respective ideologies to the same extent. This is clearly indicated by the fact that the standard deviations in the two groups of data were not zero. Statistically, standard deviation provides information regarding the extent to which the data gather around the mean (i.e. average) value. Less technically speaking, in the two sociocultural contexts some researchers embraced the respective ideologies more than the others did. It is possible that some Indonesian researchers wrote their research articles following the rhetorical structure adopted by the majority of English researchers, or vice versa.

The result of the present study substantiated Hyland's (2011, p. 181) contention that "compared with many languages English academic writing tends to be more cautious in making claims, with considerable use of mitigation and hedging." Hedges seem to be the sine qua non of current English language research articles. Nevertheless, this does not necessarily mean that research articles written in English are always more cautious in making claims than those written in any other language. Vold (2006), for example, showed that research articles written in English and those written in Norwegian were comparable in terms of their frequency of the use of hedges. Likewise, Sultan's (2011) study also found that Arabic Linguistics research articles contained more hedges than the English ones.

Martín and Pérez (2014, p. 1) rightly argued that: "In order to get their papers accepted, researchers need to meet the expectations of the members of their particular communities, especially those of the editors and reviewers of international English language journals." It could be argued that when Indonesian applied linguists wish to publish in international English-medium journals 
they might not be able to satisfy the requirements determined by their target disciplinary community. This is quite apparent from the distinct rhetorical characteristics displayed by the Indonesian applied linguists in their research articles. The international applied linguistic community demands that researchers in the field state their propositions with caution (through use of various hedging devices) so as to "open a discursive space for readers to dispute interpretations" (Hyland, 2009, p. 75). However, there is a temptation among Indonesian applied linguists to put forth their argumentation categorically when they write their research articles in English for international publication.

The finding of the present study suggests that Indonesian applied linguists may be in need of instruction that specifically focuses on when and how to hedge propositions when they write research articles in English. Such instruction would teach them "to be confidently uncertain" (Skelton, 1998, p. 39). Specific instruction is indeed necessary to promote students' knowledge of hedges. It seems that hedges cannot be acquired implicitly or incidentally through rich exposure to academic writing only; reading English research articles in their research activities may not be effective for Indonesian scholars to acquire knowledge of hedges, as attested by Hyland's (2000) study. Hyland (2000) carried out a study involving undergraduate students studying for a BA in English for Professional Communication at a Hong Kong university to examine the extent to which hedges in English academic writing were attended to during reading. Hyland found that hedges were hardly noticed by the students. To put it another way, hedges were largely invisible in academic writing. On the basis of this finding, Hyland (2000, p. 192) concluded that "there is strong evidence in this study that the efforts of academic writers to weaken their commitment and withhold certainty from their propositions may go unnoticed by L2 readers." Therefore, to reiterate, instruction that is specifically aimed at equipping EAP learners with knowledge of hedges is a pedagogically justified practice.

One might argue that researchers might deploy different rhetorical strategies depending on the target journals in which they wish to publish. Therefore, the argument goes, it would be unjustified to argue that Indonesian applied linguists would avoid hedging their propositions when they write in English for international publication only because they do not hedge their propositions sufficiently in their Indonesian research articles for local publication. While such argument might intuitively be true, there is no robust empirical finding showing that researchers vary their hedging behaviors depending upon the target 
journal in which they wish to publish. On the contrary, studies on L2 academic writing consistently report some kind of pragmatic transfer of rhetorical strategies prevalent in writers' L1 writing into their L2 writing. In a study on Spanish researchers, Alonso et al. (2012), for example, found that "hedges in academic English are perceived as indicators of a negative lack of commitment by native speakers of Spanish and pragmatic transfer appears to inhibit the use of hedges that are not common to the native language" (p. 60). No one would dispute the argument put forth by Žegarac and Pennington (2008, p. 142): "People usually approach a new problem or situation with an existing mental set: a frame of mind involving an existing disposition to think of a problem or a situation in a particular way" (italics in the original). Moreover, Applied Linguistics journal editors typically do not mention explicitly in their journal submission guidelines that authors should hedge their propositions sufficiently and/or appropriately. This would further make such rhetorical feature escape the attention of the non-native writers.

\section{CONCLUSIONS AND SUGGESTIONS}

The present need-analytic, corpus-based study is carried out to examine whether Indonesian scholars need to learn how to hedge their propositions in their English research articles written for international publications. The results showed that the English research articles contained significantly more hedges than the Indonesian research articles, suggesting that the English researchers were much more cautious in making claims than their Indonesian counterparts. Such finding implies that in order to be published in English international journals, research articles need to be presented with sufficient caution. As indicated by the rhetorical characteristics of their research articles written in Indonesian, Indonesian researchers typically did not exercise sufficient caution when promoting claims. On the basis of the result of the study it could be concluded that Indonesian scholars indeed need to be involved in a pedagogical intervention specifically designed to equip them with knowledge of hedges. This conclusion has been drawn on the assumption that when Indonesian researchers report their research in English for international publication they will employ the rhetorical characteristics they adopt when they write their research in Indonesian.

Obviously, the results of the present study need to be treated with caution. This study is subject to limitations inherent to the size and scope of the corpus used, as well as the type of data analyzed. The corpus was derived from only 
52 research articles taken from only one disciplinary field (Applied Linguistics). The conclusion that Indonesian scholars still need to learn how to hedge their propositions when they write in English for international publications might sound suspect. Future research needs to be done that analyzes a larger corpus containing research articles taken from all disciplinary domains, namely natural sciences (e.g. Physics, Biology), social sciences (e.g. Economics, Sociology), and humanities (e.g. Law, Applied Linguistics). In so doing, a more valid conclusion can be drawn. The present study analyzes research articles written in Indonesian only based upon which the Indonesian scholars' rhetorical need was determined. Although thus far there has been no robust finding indicating that researchers vary their rhetorical behavior depending upon the target journal, such possibility cannot be completely eliminated. Therefore, future research might need to consider analyzing not only the Indonesian scholars' research articles written in Indonesian, but also their English articles published for local publication.

\section{REFERENCES}

Abbuhl, R. (2006). Hedging and boosting in advanced-level L2 legal writing: The effect of instruction and feedback. In H. Byrnes, H. Weger-Guntharp \& K. A. Sprang (Eds.), Educating for advanced foreign language capacities: Constructs, curriculum, instruction, assessment (pp. 152-164). Washington, D.C.: Georgetown University Press.

Adnan, Z. (2008). Discourse structure of Indonesian research article introductions in selected hard sciences. In S. Burgess \& P. Martín-Martín (Eds.), English as an additional language in research publication and communication (pp. 39-63). Berlin, Germany: Peter Lang.

Alonso, R. A., Alonso, M. A., \& Mariñas, L. T. (2012). Hedging: An exploratory study of pragmatic transfer in nonnative English readers' rhetorical preferences. Ibérica, 23, 47-64.

Atai, M. R., \& Nazari, O. (2011). Exploring reading comprehension needs of Iranian EAP students of health information management (HIM): A triangulated approach. System, 39(1), 30-43. 
Atai, M. R., \& Shoja, L. (2011). A triangulated study of academic language needs of Iranian students of computer engineering: Are the courses on track? RELC Journal, 42(3), 305-323.

Bacha, N. N., \& Bahous, R. (2008). Contrasting views of business students' writing needs in an EFL environment. English for Specific Purposes, 27(1), 74-93.

Basturkmen, H. (2010). Developing courses in English for specific purposes. Basingstoke: Palgrave Macmillan.

Biber, D. (2009). Quantitative methods in corpus linguistics. In A. Lüdeling \& M. Kytö (Eds.), Corpus linguistics: An international handbook (Vol. 2, pp. 1286-1304). New York: Walter de Gruyter.

Bosuwon, T., \& Woodrow, L. (2009). Developing a problem-based course based on needs analysis to enhance English reading ability of Thai undergraduate students. RELC Journal, 40(1), 42-64.

Chostelidou, D. (2010). A needs analysis approach to ESP syllabus design in Greek tertiary education: a descriptive account of students' needs. Procedia - Social and Behavioral Sciences, 2(2), 4507-4512.

Cooper, A., \& Bikowski, D. (2007). Writing at the graduate level: What tasks do professors actually require? Journal of English for Academic Purposes, 6(3), 206-221.

Corder, G. W., \& Foreman, D. I. (2014). Nonparametric statistics: A step by step approach (Second ed.). Hoboken, NJ: John Wiley \& Sons.

Cowling, J. D. (2007). Needs analysis: Planning a syllabus for a series of intensive workplace courses at a leading Japanese company. English for Specific Purposes, 26(4), 426-442.

Dafouz-Milne, E. (2008). The pragmatic role of textual and interpersonal metadiscourse markers in the construction and attainment of persuasion: A cross-linguistic study of newspaper discourse. Journal of Pragmatics, 40(1), 95-113.

Field, A. (2013). Discovering statistics using IBM SPSS statistics (4th ed.). Thousand Oaks, CA: Sage Publications. 
Flowerdew, L. (2013). Needs analysis and curriculum development in ESP. In B. Paltridge \& S. Starfield (Eds.), The handbook of English for specific purposes (pp. 325-346). Malden, MA: John Wiley \& Sons Ltd.

Gee, J. P. (2012). Social linguistics and literacies (Fourth ed.). New York: Routledge.

Gee, J. P. (2015). Literacy and education. New York: Routledge.

Gözüyeşil, E. (2014). An analysis of engineering students' english language needs. Procedia - Social and Behavioral Sciences, 116, $4182-4186$.

Hyland, K. (1996). Talking to the academy: Forms of hedging in science research articles. Written Communication, 13(2), 251-281.

Hyland, K. (2000). Hedges, boosters and lexical invisibility: Noticing modifiers in academic texts. Language Awareness, 9(4), 179-197.

Hyland, K. (2006). English for academic purposes: An advanced resource book. Abington: Routledge.

Hyland, K. (2009). Academic discourse: English in a global context. London: Continuum.

Hyland, K. (2011). Academic discourse. In K. Hyland \& B. Paltridge (Eds.), Continuum companion to discourse analysis (pp. 171-184). New York: Continuum.

İnceçay, G., \& İnceçay, V. (2010). A case study on needs assessment of English language teachers. Procedia Social and Behavioral Sciences, 2(2), 317-321.

Jackson, J. (2005). An inter-university, cross-disciplinary analysis of business education: Perceptions of business faculty in Hong Kong. English for Specific Purposes, 24(3), 293-306.

Kaewpet, C. (2009). Communication needs of Thai civil engineering students. English for Specific Purposes, 28(4), 266-278.

Kassim, H., \& Ali, F. (2010). English communicative events and skills needed at the workplace: Feedback from the industry. English for Specific Purposes, 29(3), 168-182. 
Kim, H. H. (2013). Needs analysis for English for specific purpose course development for engineering students in Korea. International Journal of Multimedia and Ubiquitous Engineering, 8(6), 279-288.

Kim, S. (2006). Academic oral communication needs of East Asian international graduate students in non-science and non-engineering fields. English for Specific Purposes, 25(4), 479-489.

Klimova, B. F. (2014). Academics at faculty of informatics and management and their language needs. Procedia - Social and Behavioral Sciences, 116, $656-660$.

Lambert, C. (2010). A task-based needs analysis: Putting principles into practice. Language Teaching Research, 14(1), 99-112.

Larson-Hall, J. (2010). A guide to doing Statistics in second language research using SPSS. New York: Routledge.

Lehtonen, T., \& Karjalainen, S. (2008). University graduates' workplace language needs as perceived by employers. System, 36(3), 492-503.

Long, M. H. (2005a). Methodological issues in learner needs analysis. In M. H. Long (Ed.), Second language needs analysis (pp. 19-76). Cambridge: Cambridge University Press.

Long, M. H. (2005b). Second language needs analysis. Cambridge: Cambridge University Press.

Martín, P., \& Pérez, I. K. L. (2014). Convincing peers of the value of one's research: A genre analysis of rhetorical promotion in academic texts. English for Specific Purposes, 34, 1-13.

Mazdayasna, G., \& Tahririan, M. H. (2008). Developing a profile of the ESP needs of Iranian students: The case of students of nursing and midwifery. Journal of English for Academic Purposes, 7(4), 277-289.

Miller, D. (2011). ESL reading textbooks vs. university textbooks: Are we giving our students the input they may need? Journal of English for Academic Purposes, 10(1), 32-46. 
Moslemi, F., Moinzadeh, A., \& Dabaghi, A. (2011). ESP needs analysis of Iranian MA students: A case study of the University of Isfahan. English Language Teaching, 4(4), 121-129.

Paci, M. (2013). Needs analysis and environment analysis: Designing an ESP curriculum for the students of the Polytechnic University of Tirana. Journal of Educational and Social Research, 3(7), 425-430.

Read, J. (2008). Identifying academic language needs through diagnostic assessment. Journal of English for Academic Purposes, 7(3), 180-190.

Rostami, F., \& Zafarghandi, A. M. (2014). EAP needs analysis in Iran: The case of university students in chemistry department. Journal of language Teaching and Research, 5(4), 924-934.

Salager-Meyer, F. (2014). Writing and publishing in peripheral scholarly journals: How to enhance the global influence of multilingual scholars? Journal of English for Academic Purposes, 13, 78-82.

Schreiber, J., \& Asner-Self, K. (2011). Educational research: The interrelationship of questions, sampling, design, and analysis. Hoboken, NJ: John Wiley \& Sons.

Skelton, J. (1998). The care and maintenance of hedges. ELT Journal, 42(1), $37-43$.

Spence, P., \& Liu, G.-Z. (2013). Engineering English and the high-tech industry: A case study of an English needs analysis of process integration engineers at a semiconductor manufacturing company in Taiwan. English for Specific Purposes, 32(2), 97-109.

Stocker, J. F., \& Reddad, M. (2013). Constructing a collaborative, emergent syllabus of communicative performances in a nursing English course in Taiwan. RELC Journal, 44(2), 177-194.

Street, B. (2003). What's "new" in new literacy studies? Critical approaches to literacy in theory and practice. Current Issues in Comparative Education, 5(2), 77-91.

Sultan, A. H. J. (2011). A contrastive study of metadiscourse in English and arabic linguistic research articles. ACTA LINGUISTICA, 5(1), 28-41. 
Sanjaya, Sitawati, \& Suciani, Comparing Hedges in Published Research Articles 227

Swales, J. M. (1990). Genre analysis: English in academic and research settings. Cambridge: Cambridge University Press.

Taillefer, G. F. (2007). The professional language needs of Economics graduates: Assessment and perspectives in the French context. English for Specific Purposes, 26(2), 135-155.

Vold, E. T. (2006). Epistemic modality markers in research articles: A crosslinguistic and crossdisciplinary study. International Journal of Applied Linguistics, 16(1), 61-86.

Žegarac, V., \& Pennington, M. C. (2008). Pragmatic transfer. In H. SpencerOatey (Ed.), Culturally speaking: Culture, communication, and politeness theory (Second ed., pp. 141-163). London: Continuum. 